\title{
Evaluation of Nursing Students' Knowledge Levels About Peripheral Intravenous Catheter Insertion Skill
}

\author{
Hanife Durgun ${ }^{1}$, Berna Köktürk Dalcalı², Şeyda Can $^{3}$ \\ ${ }^{1}$ Health Science Faculty, Depermant of Nursing, Ordu University, Ordu, Turkey \\ ${ }^{2}$ Health Science Faculty, Depermant of Nursing, Bandırma Onyedi Eylul University, Balıkesir, Turkey \\ ${ }^{3}$ Health Science Faculty, Depermant of Nursing, Yalova University, Yalova, Turkey
}

Received: 18 March 2020, Accepted: 12 April 2020, Published online: 30 August 2020

(C) Ordu University Institute of Health Sciences, Turkey, 2020

\begin{abstract}
Objective: Peripheral intravenous catherization procedures are frequently performed on hospitalized patients. The application of the peripheral intravenous catherization is one of the most frequently used invasive nursing procedures. Although peripheral intravenous catheterization is the most commonly performed basic nursing skill and it is the skill that causes the most anxiety during clinical practices. Thereforei this study was conducted to examine nursing students' levels of knowledge about peripheral intravenous catheterization.

Methods: This descriptive and correlational study's data were collected from 302 nursing students from February 2019 to April 2019 during the 2018-2019 academic year. The study data were collected using an introductory information form, the Peripheral Intravenous Catheterization Information Form and in face-toface interviews.

Results: The students' mean score for knowledge levels about peripheral intravenous catheterization was $66.53 \pm 15.00$. The students who had graduated from vocational schools of health and the students who were in their fourth year of study had higher levels of knowledge about peripheral intravenous catheterization, and this was a statistically significant difference with the other students.

Conclusion: The nursing students' level of knowledge about peripheral intravenous catheterization increased with years of study, and they had moderately high levels of knowledge about it during their 4-year undergraduate education.
\end{abstract}

Key words: Peripheral intravenous catheterization, Nursing students, Nursing education

Suggested Citation: Durgun H, Kokturk Dalcalı B, Can S. Evaluaion of Nursing Students' Knowledge Levels About Peripheral Intravenous Catheter Insertion Skill. Middle Black Sea Journal of Health Science, 2020; 6(2):145-151.

\section{Address for correspondence/reprints:}

Hanife Durgun

Telephone number: +90(452) $2345200(6435)$

ORCID-ID 0000-0003-1622-8184

E-mail: hanife.balik@gmail.com
DOI: $\quad 10.19127 / \mathrm{mbsjohs} .705914$

Note: This study was presented as an oral presentation at the 5th National and 1st International Nursing Care Congress on December 6-8, 2019. 


\section{Introduction}

The nursing profession is a practical discipline that requires both theoretical knowledge and practical skills to be combined in a harmonious way (Schoening et al., 2006). Nursing students should develop themselves affectively and achieve professional efficiency in psychomotor skills. In this context, nursing practices include the reflection of theoretical knowledge, affective competencies in the clinical setting, and psychomotor skills such as practice and management in care actions (Aydogan, 2016). Psychomotor skill; coordinated muscle activities used during the performance of a work, guided by conscious mental activity (Mete and Uysal, 2009; Sen, 2012).

Every psychomotor skill requires physical, cognitive and affective skills (Simsek et al., 2018).Peripheral intravenous catheterization (PIVC) is the most commonly performed basic nursing skill and one of the most important modern treatment methods used in hospitals (Aydin and Arslan, 2018; Kus and Buyukyılmaz, 2017; Sarı et al., 2016). PIVC is used commonly (Tokizawa et al., 2017) with approximately $80 \%$ of hospital patients (Rickard et al., 2012; van Loon et al., 2018; Webster et al., 2013). An average of more than 300 million PIVCs a year are performed in the United States and England (Abadi et al., 2013; Aydın and Gurol Arslan, 2018; Keleekai et al., 2016; Wallis et al., 2014). PIVC is one of the hardest nursing skills to teach and causes the most anxiety during clinical practices (Bayar et al., 2009; Erdem, 2018). Students feel so much anxiety because they do not think they have sufficient knowledge about and skills in PIVC, because they do "not/cannot get sufficient practice, and because PIVC is an invasive practice that can hurt patients (Houghton et al., 2013; Ozturk and Dinc, 2014).

Nurses' responsibilities include knowing the relevant vein anatomy well, determining the area where PIVC is to be performed, choosing the catheter that suits patients' age and treatment, knowing the proper PIVC methods and principles and knowing about potential complications (Uzun, 2019; Aydin and Gurol Arslan, 2018; Aygun and Erten, 2011; Carroll and Bennett, 2015). These competencies must be acquired by nursing students during their student days. However, the development of students' skills in practice is hindered by: insufficient numbers of academic staff and excessive numbers of students in nursing departments, insufficiencies in clinical practice fields, non-equipped and insufficient numbers of skill laboratories, discharging patients quickly and the recent rise in the importance of patient safety and patient rights. (Goris et al., 2014;
Sendir, 2013; Sendir and Coskun, 2016). This study was conducted to evaluate nursing students' levels of knowledge about PIVC insertion skill.

The main research questions are as follows:

1. What are the students' levels of knowledge about PIVC?

2. Is there a difference among PIVC knowledge levels according to the socio - demographic characteristics of nursing students?

\section{Methods}

\section{Study design population and sampling}

This is a descriptive cross-sectional study. The descriptive cross-sectional survey questions were answered in 2019. The target population was nursing faculty students. The study population included 404 students in the nursing department of a faculty of health sciences in Turkey during the 2018-2019 academic year. The total number of samples was calculated as 252 according to $5 \%$ acceptable error, $99 \%$ confidence level. The sample was increased by $20 \%$ to avoid an effect of any possible loss of data, bringing the total to 302 students and 302 students participated in the study.

\section{Ethical considerations}

Before starting the research, the written consents of the research institution were obtained. The research protocol was approved by the ethics committee (Decision no: 2019/65). Students participating in the research signed their consent for participation in the study.

\section{Data Collection Instruments}

The study data were collected using an introductory information form, the PIVC Information Form and in face-to-face interviews.

Personal information form was prepared by the researchers considering relevant literature (Aydin and Arslan, 2018; Erdem, 2018). It included 7 questions related to sociodemographic characteristics such as age, sex, graduated high school, what class of students, whether they perceived themselves as suitable for the profession of nursing, and whether nursing was their choice.

The PIVC Information Form was developed in a postgraduate thesis entitled "An Examination of the Effect of Simulation-based Learning in Developing the Skill of Peripheral Intravenous Catheter Insertion." It includes 10 questions prepared by the researcher in accordance with the literature to determine students' levels of knowledge about PIVC. The lowest possible score is 0 , and the highest is 100 . 
Higher PIVC scores indicate higher levels of knowledge about PIVC.

\section{Data Collection}

The data were collected by the researchers in the classroom between 10 to 15 minutes by using face to face interview technique.

\section{Data and Statistical Analyses}

The data were analyzed using the Statistical Package for Social Sciences 22.0 (SPSS 22.0). Descriptive statistics (percentage, mean, and standard deviation) were applied to students' demographic characteristics. Kolmogorov- Smirnov test was conducted to examine normal distribution. Independent-Sample $T$ test was utilized for comparison of the quantitative data showing normal distribution. For data normal distribution, Anova test was used for comparison of groups more than two. The value of $\mathrm{p}<0.05$ was considered to be statistically significant.

\section{Results}

The study sample included 302 nursing students. Most of the participants were male (76.2\%), and all of them were in the age group of 18 to 25 years old. Their mean age was $20.24 \pm 1.46$. Of the participants, $64.9 \%$ had graduated from Anatolian high schools. The largest number of them were third year students $(30.5 \%)$. Of the participants, $47.0 \%$ thought that nursing suited them partially, $71.6 \%$ chose nursing willingly, and $71.2 \%$ chose nursing because they think it will be easy to find a job after graduation (Table 1)

Table 1. Demographic characteristics of the nursing students

\begin{tabular}{|c|c|c|c|c|c|}
\hline Variable & Categories & $(\%)$ & $\mathrm{n}$ & M & SD \\
\hline Age (years) & $18-25$ & & 302 & 20.24 & 1.46 \\
\hline \multirow[t]{2}{*}{ Gender } & Male & 76.2 & 230 & & \\
\hline & Female & 23.8 & 72 & & \\
\hline \multirow[t]{4}{*}{ Year of study } & 1st Year & 27.0 & 86 & & \\
\hline & 2nd Year & 22.6 & 72 & & \\
\hline & 3rd Year & 30.5 & 97 & & \\
\hline & 4th Year & 19.8 & 63 & & \\
\hline \multirow{4}{*}{$\begin{array}{l}\text { High school } \\
\text { type }\end{array}$} & Vocational School of Health & 18.9 & 57 & & \\
\hline & Anatolian High School & 64.9 & 196 & & \\
\hline & Science High School & 3.0 & 9 & & \\
\hline & Other & 13.2 & 40 & & \\
\hline \multirow{3}{*}{$\begin{array}{l}\text { Believing } \\
\text { nursing suits } \\
\text { them }\end{array}$} & Yes & 46.7 & 141 & & \\
\hline & No & 6.3 & 19 & & \\
\hline & Partly & 47.0 & 142 & & \\
\hline \multirow[t]{2}{*}{ Chose nursing } & Willingly & 216 & 71.5 & & \\
\hline & Unwillingly & 86 & 28.5 & & \\
\hline \multirow{4}{*}{$\begin{array}{l}\text { Reasons for } \\
\text { choosing } \\
\text { nursing }\end{array}$} & Ease of employment & 215 & 71.2 & & \\
\hline & My family's request & 47 & 15.6 & & \\
\hline & Want to be a nurse & 35 & 11.6 & & \\
\hline & Peer suggestions & 5 & 1.7 & & \\
\hline
\end{tabular}


Table 2. PIVC Score

\begin{tabular}{lccc}
\hline & n & Min-Max & Mean \pm SD (Median) \\
\hline PIVC Score & 302 & $25-100$ & $66.53 \pm 15.00(65)$ \\
\hline
\end{tabular}

Their mean score for knowledge about PIVC was $66.53 \pm 15.00$. Their lowest score was 25 , and their highest was 100 (Table 2).

Table 3. Evaluation of the students' knowledge levels about PIVC according to their socio-demographic characteristics

\begin{tabular}{|c|c|c|c|c|c|c|c|}
\hline Variable & & $\mathrm{n}$ & Mean & $\mathrm{SD}$ & $\mathrm{p}$ & $\mathrm{t}$ - value & $\mathrm{df}$ \\
\hline \multirow{3}{*}{ Gender } & Male & 230 & 66.63 & 14.75 & \multirow[t]{2}{*}{0.851} & \multirow[t]{2}{*}{0.187} & \multirow[t]{2}{*}{300} \\
\hline & Female & 72 & 66.25 & 15.86 & & & \\
\hline & & & & & & F Value & \\
\hline \multirow{4}{*}{ Year of study } & 1st Year & 93 & 65.268 & 15.644 & \multirow[t]{4}{*}{0.029} & \multirow{4}{*}{3.052} & \multirow{4}{*}{3} \\
\hline & 2nd Year & 91 & 64.120 & 13.836 & & & \\
\hline & 3rd Year & 78 & 68.141 & 15.936 & & & \\
\hline & 4th Year & 40 & 71.875 & 12.894 & & & \\
\hline \multirow{5}{*}{ High school type } & $\begin{array}{l}\text { Vocational School of } \\
\text { Health }\end{array}$ & 57 & 72.631 & 12.287 & \multirow{5}{*}{0.006} & \multirow{5}{*}{4.275} & \multirow{5}{*}{3} \\
\hline & Anatolian High School & 196 & 65.510 & 15.892 & & & \\
\hline & & & & & & & \\
\hline & Science High School & 9 & 65.555 & 11.023 & & & \\
\hline & Other & 40 & 63.125 & 12.744 & & & \\
\hline \multirow{4}{*}{$\begin{array}{l}\text { Believing nursing suits } \\
\text { them }\end{array}$} & Yes & 141 & 67.269 & 16.162 & \multirow[t]{3}{*}{0.728} & \multirow[t]{3}{*}{0.318} & \multirow[t]{3}{*}{2} \\
\hline & No & 19 & 65.526 & 11.890 & & & \\
\hline & Partly & 142 & 65.950 & 14.228 & & & \\
\hline & & & & & & t- value & \\
\hline \multirow[t]{2}{*}{ Chose nursing } & Willingly & 216 & 66.481 & 15.667 & \multirow[t]{2}{*}{0.056} & \multirow[t]{2}{*}{-0.107} & \multirow[t]{2}{*}{300} \\
\hline & Unwillingly & 86 & 66.686 & 13.297 & & & \\
\hline \multirow[t]{4}{*}{$\begin{array}{l}\text { Reasons for choosing } \\
\text { nursing }\end{array}$} & Ease of employment & 215 & 66.255 & 15.672 & \multirow{4}{*}{0.568} & \multirow{4}{*}{0.675} & \multirow{4}{*}{3} \\
\hline & My family’s request & 47 & 68.723 & 12.089 & & & \\
\hline & Want to be a nurse & 35 & 64.714 & 13663 & & & \\
\hline & Peer suggestions & 5 & 71.000 & 20.736 & & & \\
\hline
\end{tabular}

$t=$ Independent -samples $t$-test $\quad F=O n e$ way Anova Test 
Comparing the students' mean scores and their socio-demographic characteristics showed that gender, believing that the nursing profession suited them, choosing nursing willingly and the reasons for choosing nursing did not affect their mean score. However, high school type and year of study affected their levels of knowledge about PIVC. The students who had graduated from vocational schools of health and the students who were in their fourth year of study had higher levels of knowledge about PIVC, and this was a statistically significant difference with the other students $(\mathrm{p}=0.006, \mathrm{p}=0.029)$ (Tablo 3).

\section{Discussion}

PIVC is one of the most invasive applications where students experience the most stress among nursing practices. (Forsberg and Engström, 2018). This practice is a difficult skill to learn for nursing students and can cause many complications if not done effectively (Kus and Buyukyilmaz, 2017). In order to avoid complications, students must have sufficient knowledge and psychomotor skills for PIVC application before encountering a real patient.

This study found the nursing students' mean PIVC score on the PIVC as $66.53 \pm 15.00$. On a scale of 100 , the students' levels of knowledge about PIVC were above the median value. As a result of the study they conducted with nursing students, Cevik et al. (2019) found that nursing students' mean score was 77.66 \pm 9.42 , Ismailoglu and Zaybak (2018) found that nursing students' mean score was $65.56 \pm 12.91$. In their study examining the students' level of knowledge regarding PIVC practice, Aydın and Arslan (2018) also found that nurses had moderately high levels of knowledge about PIVC. Our finding is in line with similar findings by prior studies. The nursing students had moderate levels of knowledge about PIVC throughout their education, which may be related to their not being able to perform it in practice very often.

In the study, female students were found to have higher PIVC score than male students. When similar studies in the literature were examined, it was found that there was no data for this finding. In the study, the high score of female students was interpreted as that women may be related to the development of fine motor skills than men.

When the PIVC scores of the students were examined according to the grade level of the study, it was determined that the students in the fourth grade had higher PIVC scores than the students in the other three study year. This finding of the study suggested that students in the fourth grade reinforced their theoretical knowledge with long-term clinical practice experiences.

Examining the high school from which students graduated and students' level of knowledge regarding PIVC practice found that students who had graduated from vocational schools of health had higher levels of knowledge about PIVC than students who had graduated from other high school types, and this difference was statistically significant $(p<0.05)$. The students who attended vocational schools of health performed PIVC many times in clinical practices, which may be an effective way to acquire this skill. Similarly, the fourth-year students had higher levels of knowledge about PIVC than those in other years of study, and this difference was statistically significant $(p<0.05)$. Being qualified in cognitive, affective and psychomotor fields is significant for efficient learning in nursing education (Eker et al., 2014). One of the fundamental points that Benner notes in her novice to expert model is that nursing knowledge is based on practice and improves with time (Koc et al., 2018). Study data obtained in the light of the literature indicates that students who perform or observe PIVC in the clinic have higher levels of knowledge about PIVC.

\section{Limitations of the study}

The study's significant limitation is the fact that it was restricted to a group of nursing students in Turkey. Therefore, the results cannot be generalized.

\section{Conclusion}

The nursing students had at least moderate levels of knowledge about PIVC throughout their education, but their levels of knowledge about PIVC also increased with years of study. Another factor that affected the students' level of knowledge about PIVC was the type of high school they attended. The students who had graduated from vocational schools of health had higher levels of knowledge about PIVC. Evaluating these results together shows that levels of knowledge about PIVC, one of the important psychomotor skills in nursing, increases with experience. 
Ethics Committee Approval: Ethics committee approval was received for this study from Ordu University Clinical Research Ethics Committee. (KAEK 2019-65).

Peer-review: Externally peer-reviewed.

Author Contributions: Concept -HD; Design- HD, BKD, SC; Supervision-HD, BKD, SC; MaterialsHD; Data Collection and/or Processing-HD; Analysis and/or Interpretation- HD, BKD; Literature ReviewHD, BKD, SC; Writing- HD, BKD, SC Critical Review- HD, BKD, SC.

Conflict of Interest: No conflict of interest was declared by the authors.

Financial Disclosure: The authors declared that this study hasn't received no financial support.

\section{References}

Abadi P, Etemadi Su, Abed Saeedi ZH. (2013). Investigating Role of Mechanical and Chemical Factors in the Creation of Peripheral Vein Inflammation in Hospitalization Patients in Hospital in Zahedan, Iran. Life Sci J 2013; 10 (1s): 379-383.

Aydin S, Arslan GG. Evaluation of Nurses' Knowledge Levels about Peripheral Intravenous Catheter Initiatives. DEUHEFED 2018; 11(4): 290-299.

Aydogan S. Ethical Problems of Nursing Students Related to Acquisition of Clinical Skills. Türkiye Biyoetik Dergisi 2016; 3(2): 120-123.

Aygun M, Erten HA New Approch In Nursing Practice: Ultrasound-Guided Periferal Intravenous Catheterization. HEMAR-G 2011; 1: 61-70.

Bayar K, Cadır G, Bayar B. Determination Thought and Anxiety Levels of Nursing Students Intended for Clinical Practice. TAF Preventive Medicine Bulletin 2009; 8(1): 37-42.

Carroll H, Bennett S. Guideline: Peripheral intravenous catheter (PIVC). Queensland Government 2015. Available from: https://www.health.qld.gov.au/_data/assets/pdf_ file/0025/444490/icarepivc-guideline.pdf.

Cevik K, Midilli TS, Ergin E. The Relationship of Nursing Students' Knowledge and Skill Levels with Exam Anxiety Regarding Parenteral Drug Applications. Manisa Celal Bayar University Journal of Institute of Health Science 2019; 6(1): 31-38.

Eker F, Açıkgöz F, Karaca A. Occupational Skill Training through the Eyes of Nursing Students. DEUHEFED 2014; 7(4): 291-294.
Forsberg A, Engström Å. Critical care nurses' experiences of performing successful peripheral intravenous catheterization in difficult situations. J Vasc Nurs 2018;36(2):64-70.

Goris S, Bilgi N, Bayındır SK. Use of Simulation in Nursing Education. J DU Health Sci Inst 2014; 1(2): 25-29.

Houghton CE. Casey D, Shaw D, Murphy K. Students' Experiences of Implementing Clinical Skills in the Real World of Practice. JCN 2013; 22(13-14): 1961-1969.

Ismailoglu EG, Zaybak A. Comparison of the Effectiveness of A Virtual Simulator with A Plastic Arm Model in Teaching Intravenous Catheter Insertion Skills. CIN 2018; 36(2): 98105.

Keleekai NL, Schuster CA, Murray CL, King MA, Stahl BR, Labrozzi LJ, et al. Improving Nurses' Peripheral Intravenous Catheter Insertion Knowledge, Confidence, And Skills Using A Simulation-Based Blended Learning Program: A Randomized Trial. Simulation in Healthcare 2016; 11(6): 376-384.

Koc Z, Çınarlı T, Sener A, Kızıltepe SK. Patrıcıa Benner: Clinical Wisdom and Skill Acquisition in Nursing Practices. ACU Sağlık Bil Derg 2018; 9(1): 1-12.

Kus B Buyukyilmaz F. Current Evidence for Prevention of the Complications Related to Peripheral Intravenous Catheterization: Systematic Review. FNJN 2017; 25(3): 209-217.

Mete S, Uysal N. Implementation of An Education Model for Nursing Skills Development. DEUHEFED 2009; 2(3): 115-123.

Ozturk D, Dinc L. Effect of Web-Based Education on Nursing Students' Urinary Catheterization Knowledge and Skills. Nurse Education Today 2014; 34(5): 802-808

Sarı D, Eser İ, Akbıyık A. Phlebitis associated with Peripheral Intravenous Catheters and Nursing Care. JHS 2016; 13(2): 2905-2920.

Schoening AM, Sittner AJ, Todd MJ. Simulated Clinical Experience, Nursing Students' Perceptions and Educators' Role. Nurse Educator 2006; 31(6): 253258.

Sen H. Guide Principles of Psychomotor Skills Teaching in Nursing: Sample of Chest Compression. DEUHEFED 2012; 5(4):180-184.

Sendir M. Use of Simulation in Women's Health Nursing Education. FNJN 2013; 21(3): 205-12.

Sendir M, Coskun EY. A Technological Step in Nursing Education: IM ventro-sim. JAREN 2016; 2(2): 103-108 
Simsek M, Çonoğlu G, Orgun F. Evaluation of Basic Nursing Skills Planned to be Acquired during Nursing Education. Ege Universitesi Hemşirelik Fakültesi Der. 2018; 34(1):1-25.

Rickard CM, Webster J, Wallis MC, Marsh N, McGrail MR., French V, et al.. Routine Versus Clinically Indicated Replacement of Peripheral Intravenous Catheters: A Randomised Controlled Equivalence Trial. The Lancet 2012; 380 (9847): 1066-1074.

Uzun S. "Intravenous fluid therapy". Aști, T., Karadağ, A. (Eds.). Nursing Fundamentals: Science and Art of Nursing. Istanbul: Academy Press and Publishing, 2019. p.699-712

Van Loon FHJ, Buise MP, Claassen JJF, Dierick-van Daele ATM, Bouwman, ARA. Comparison of Ultrasound Guidance with Palpation and Direct Visualisation for Peripheral Vein Cannulation in Adult Patients: A Systematic Review and MetaAnalysis. BJA 2018; 121(2): 358-366.

Wallis MC, Mc Grail M, Webster J, Marsh N, Gowardman J, Playford EG, Rickard CM. Risk Factors for Peripheral Intravenous Catheter Failure: A Multivariate Analysis of Data from a Randomized Controlled Trial. Infection Control \& Hospital Epidemiology 2014; 35(1): 63-68.

Webster J, Osborne S, Rickard CM, New K. Clinically-Indicated Replacement Versus Routine Replacement of Peripheral Venous Catheters. Cochrane Database of Systematic Reviews 2015; 14;(8): CD007798.

Tokizawa Y, Tsujimoto T, Inoue T. Duration of Vasodilation for Peripheral Intravenous Cannulation, as Induced by a Thermal Stimulus on the Forearm. BRN 2017; 19(2): 206-212. 